DOI 10.15393/j9.art.2017.4261

УДК 821.161.1.09“18“

Валентина Ивановна Габдуллина

Алтайский государственный педагогический университет

(Барнаул, Российская Федераиия)

vigv@mail.ru

\title{
ТЮРКСКИЙ МИР РУССКОГО ПИСАТЕЛЯ: «СКАЗАНИЕ О СИБИРСКОМ ХАНЕ, СТАРОМ КУЧУМЕ» Д. Н. МАМИНА-СИБИРЯКА*
}

Аннотация. В статье рассматриваются особенности авторской концепции Востока и принципов воссоздания образа жизни и менталитета тюркских народов в «Восточных легендах» Д. Н. Мамина-Сибиряка в контексте общего для русской литературы рубежа XIX-XX вв. интереса к ориентализму. На материале «Сказания о сибирском хане, старом Кучуме» анализируется процесс перерастания поэтической стилизации в индивидуально-авторский вариант жанровой формы в результате осмысления, эстетического освоения и воплощения инонациональной культуры, фольклорно-мифологической образности в художественном тексте русского писателя. В «Сказании...» наглядно проявляется стремление автора показать жизнь кочевых народов «изнутри», выйти за рамки сложившихся оценочных стереотипов относительно населяющих Сибирь народов, которые закрепились в сознании русских в период завоевания Сибири войсками русского царя под предводительством атамана Ермака. Для сравнительного анализа привлекаются летописные источники (Есиповская летопись). Исследование ведется с позиций культурно-исторического, имагологического и мотивного подходов.

Ключевые слова: Д. Н. Мамин-Сибиряк, «Восточные легенды», ориентализм, жанровая модель, менталитет, традиция, имагология

И нтерес к восточной тематике и образности характерен для русской литературы начиная с самого раннего периода формирования и на всем протяжении ее развития, что, очевидно, связано с особым положением России между европейским и азиатским миром. Русский менталитет соединил в себе приметы европейского и восточного мировосприятия, что неоднократно отмечено русской классической литературой и философией. Появление «Восточных легенд» Д. Н. МаминаСибиряка происходит на фоне общего для русской культуры рубежа XIX-XX вв. увлечения ориентализмом, проявившимся 
в литературе в обращении авторов к восточной мифологии, фольклору, философии, к изображению экзотических по отношению к русской культуре образов, мотивов, сюжетов, представлений о мире, свойственных восточному мировоззрению. В литературе популярны стали восточные сказки, легенды, притчи. При этом перед автором, изображающим инонациональный мир в традиционных для иной культуры жанровых формах, возникает опасность впасть в стилизацию и создать вторичные по отношению к оригиналам произведения. Как замечает О. В. Зырянов, стилизация «возникает в ситуации эстетической дистанции между современным автором и неким авторитетным “образцом” того или иного литературного жанра» [6, 71]. В случае с «Восточными легендами» Мамина-Сибиряка происходит перерастание стилизации, к которой, безусловно, прибегает автор, в креативный текст - индивидуально-авторскую вариацию жанровой формы.

«Восточные легенды» Мамина-Сибиряка неоднократно привлекали внимание исследователей. Большой вклад в изучение его творчества в целом и, в том числе, «Восточных легенд» внесли уральские литературоведы, занимавшиеся сбором биографического материала о своем земляке, популяризацией творчества писателя, публикацией его произведений и их анализом. Особая роль в этом принадлежит И. А. Дергачеву [3], [4]. Изучением фольклорной основы произведений писателя занимались М. Г. Китайник [7] и Б. Д. Удинцев [16]. Историческую и этнографическую основу произведений Мамина-Сибиряка исследовали О. К. Лагунова [8] и Л. С. Соболева [15]. В работах Е. Е. Приказчиковой исследуется философское содержание и мифологическая символика «Восточных легенд» [13], [14]. В связи с изучением «Восточных легенд» Мамина-Сибиряка в литературоведении поднимался вопрос о жанровой природе вошедших в цикл произведений. С точки зрения В. А. Михнюкевича, писатель прибегал в них к искусной стилизации. «Как известно, даже авторитетные ученые-ориенталисты и литературные критики воспринимали эти произведения как обработки подлинных восточных легенд и сказаний. Писатель же начисто отрицал существование каких бы то ни было фольклорных образцов для него. 
Другими словами, перед нами искусная стилизация (это касается и сюжетики, и композиции, и языка)», - отмечает исследователь [10, 61]. Как пишет Е. Е. Приказчикова, у Мамина-Сибиряка был свой Восток, и «этот Восток был наполнен для писателя оригинальной мифологической символикой, позволяющей в значительной степени углубить наши представления об эстетическом значении “восточных" легенд в творчестве писателя» $[13,27]$.

Нас интересуют особенности авторской концепции Востока и принципов воссоздания образа жизни и менталитета тюркских народов, то есть взгляд на «Восточные легенды» с позиции имагологического подхода. В последнее время в российской науке активно развивается литературоведческая имагология, о чем свидетельствуют, например, работы Е. Ю. Артемовой [1], В. Б. Земскова [5], Н. П. Михальской [9], а также диссертации по имагологической проблематике А. Р. Ощепкова [11], Е. В. Папиловой [12]. Имагология в литературоведении совмещает в себе филологическую и культурологическую методологию при изучении образа «чужой» культуры, национальных и этнических стереотипов, чужого менталитета, клише и мифов, зафиксированных в литературе или в творчестве конкретного писателя. «Восточные легенды» Мамина-Сибиряка представляют интерес с точки зрения осмысления, творческого освоения и воплощения инонациональной культуры фольклорно-мифологической и художественной образности в тексте русского писателя.

В цикл «Восточных легенд» (1898) Мамина-Сибиряка вошло пять произведений: «Баймаган», «Майя», «Лебедь Хантыгая», «Слезы царицы», «Сказание о сибирском хане, старом Кучуме». В качестве источников мотивов и сюжетов для автора послужили легенды, предания, сказки разных народов, населявших восточные земли Российской империи. В «Восточных легендах» упоминаются татары, киргизы (так в XIX веке называли казахов), племена ногаев, вогулов и остяков.

Называя свои легенды «восточными», Мамин-Сибиряк безусловно учитывает особенности этого жанра, характерные для восточной культуры и литературы. Сложность в том, что автор - носитель инонационального (русского) менталитета - 
для реализации художественного замысла должен встать на позицию тюркоязычного сказителя, носителя иного сознания, иных представлений о мире. Задача писателя состоит в том, чтобы передать взгляд кочевника на легендарные и исторические события. Обращаясь к изображению жизни «другого народа», Мамин-Сибиряк стремится не только к точному воспроизведению исторических фактов и легендарных событий и образов, но и к положительной поэтической презентации инонародного образа жизни, обычаев и традиций, что зачастую приходит в противоречие со сложившимися в русской культуре и сознании русских людей (к которым принадлежит и сам автор) стереотипами представлений о кочевниках.

Особое место в «Восточных легендах» занимает «Сказание о сибирском хане, старом Кучуме», которое замыкает цикл, находясь, таким образом, в сильной позиции с точки зрения проявления авторской интенции. В «Сказании...» наглядно проявляется стремление автора показать жизнь кочевых народов «изнутри», выйти за рамки сложившихся оценочных стереотипов относительно населяющих Сибирь народов, которые закрепились в сознании русских в период завоевания Сибири войсками русского царя под предводительством атамана Ермака. Сохранилось множество устных и письменных свидетельств, которые передают отношение русского народа к событиям этого времени. Существуют летописные источники, представляющи официальную версию исторического события, которые опираются как на документы, так и на устные свидетельства и предания. Так, в тексте сибирской летописи (Есиповской), написанной дьяком Тобольского архиерейского дома Саввой Есиповым, отряд Ермака изображается как «орудие бога» в борьбе с «неверными»:

Посла бог очистити место святини и победити бесерменского царя Кучюма и разорити богомерзкая их и нечестивая капища, но и еще быша вогнеждение зверем и водворение сирином ${ }^{1}$.

Народы, населяющие сибирское ханство, именуются в летописи «погаными», «неверными» и «окаянными». О гибели Ермака сказано как об «убиении атамана Ермака и казаков от 
поганых татар» (95). Смерть самого хана Кучума изображается как негероическая:

Царь же Кучюм убежал в Нагайскую землю и тамо убиен от нагайских людей. И тако скончася житие его (97).

Действие «Сказания о сибирском хане, старом Кучуме» разворачивается в особом хронотопе, который можно определить как «легендарный». Автор изображает инонациональный мир, вписывающийся в географическое пространство от киргизских (казахских) степей и берегов Иртыша и Оби до Уральских гор. Художественный хронотоп обладает определенными приметами. С одной стороны, он ориентирован на конкретное географическое пространство - в тексте сказания названы реальные топонимы: названия рек (Иртыш, Тобол, Урал, Обь), селений и городов (Москва, Камень, Бухара и др.). С другой стороны, многие топонимы, которые звучат экзотически, очевидно, почерпнуты автором из сибирских легенд и преданий. Упоминаются названия городов и селений (Епанчи, Искер, Цимги, Наоболак, Сауксан), рек, озер (Карача-Куль, Кара-Куль, Вагай, Тура), гор (Чувашья гора).

Художественное время в сказании соотносится с конкретным историческим временем - с началом освоения Сибири Русью, похода Ермака в Сибирь с целью завоевания Сибирского ханства и присоединения Сибири к России (1581-1585). Присутствие фантастических элементов, архетипов, сказочных формул делает художественный мир «Сказания...» мифологизированным.

Главным элементом пространственной картины мира «Восточных легенд» выступает степь как место обитания кочевых народов. Описания степи входят во все произведения цикла. В киргизской сказке «Баймаган», открывающей цикл, описание степи становится своеобразным лейтмотивом, символизирующим красоту, вечность и неизменность природы:

Киргизская степь была такъ же хороша, какъ десять льтъ назадъ, такъ же весной она покрывалась цвътами и ковылемъ, тотъ же игралъ по ней степной вътеръ, а зимой волкомъ завывали снъжныя мятели...2 
В «Сказании о сибирском хане, старом Кучуме» образ степи становится ключевым и приобретает постоянные коннотации, обусловленные не только его климатическими, топографическими, пейзажно-ландшафтными характеристиками. Степь родное для героев пространство: «...степь вспоила и вскормила хана Кучюма» $(12,251)$, и он не изменил матери-степи.

Природные силы степи включены в развитие событий как действующие лица, о чем свидетельствуют, например, подобные выражения автора-сказителя:

Обманули его <Карачу > свои собственные глаза, обманула неоглядная степь... $(12,255)$.

В легендах, переданных Маминым-Сибиряком, большое место отводится анималистическим образам как важнейшему элементу бытовой и ментальной картины мира кочевых народов. В «Сказание о сибирском хане, старом Кучуме» автор вводит предание о возникновении разных народов:

Три женщины мучились въ родахъ: схватилась одна за землю - отъ нея произошли китайцы, другая схватилась за дерево - родились русскіе, за конскую гриву схватилась третья и всъ Ђздящіе на конъ считаютъ ее своей матерью $(12,252)$.

Так мотивируется роль и функции коня как тотемного животного, почитаемого в кочевых племенах. В не менее важной роли в преданиях выступает волк:

Отъ волка зачала эта третья, и волчья кровь осталась въ степи. Поэтому не боится сердце джигита ни волчьихъ глазъ ни волчьяго воя, а въ буранъ оно веселится, какъ на праздникъ $(12,252)$.

Два этих тотема - конь и волк - постоянно упоминаются в текстах легенд при характеристике кочевых народов: татар и киргизов (казахов), ногаев (ногайцев).

Автор «Восточных легенд» объясняет образ жизни и менталитет разных народов, опираясь на это предание о трех женщинах-прародительницах. О китайцах сказано: «У первой матери смирныя дъти - не любятъ войны»; о русских: «...у второй матери - дъти бьють только чужихъ и чужое любятъ больше своего»; о кочевых народах: «...дъти третьей матери страшны для всъхъ - не растетъ трава, гдъ они пройдутъ. 
Міръ принадлежитъ имъ, ъздящимъ на конъ... Но волчья кровь не знаетъ покоя: когда нътъ войны съ чужими - бьются свои. Горько оплакивала эта третья мать и раненыхъ, и убитыхъ, и взятыхъ въ плънъ» $(12,252)$.

Анималистические образы коня и волка выполняют в произведениях Мамина-Сибиряка различные функции. Их символика восходит к древним мифам и фольклору. Образ коня постоянный атрибут при описании мирного и боевого быта тюркских народов - становится сквозным в «Восточных легендах». Наряду с символической, этот образ выполняет психологическую функцию. С его помощью автор передает психологическое состояние своих героев, для которых конь является атрибутом жизни, а его потеря означает смерть. Так, например, описывается скачка мурзы Карачи от преследователей:

...загналъ Карача уже двухъ лошадей, - осталась посльдняя, третья, и, если она не вынесетъ, - пропало все. <...> Третья лошадь стала задыхаться - это пришель конець хитрому Карачъ $(12,255)$.

Не менее значим в легендах образ волка. Волк для тюркских народов связан с преданиями о родовом тотеме. Об этом пишет Лев Гумилев, приводя сходные мифы о происхождении разных тюркских родов, называя их «потомками волчицы» [2]. С волком в «Сказании о сибирском хане, старом Кучуме» сравниваются герои, наделенные недюжинной силой, смелостью и мудростью: «Смълъе голоднаго волка мурза Карача» $(12,263)$; Махмедкул «волкомъ ходилъ на Камень» $(12,253)$; «Какъ волкъ въ камышахъ, сидитъ Кучюмъ подъ Чувашьей горой» $(12,246) ;$ «Не видятъ ничего слЂпые глаза стараго Кучюма, но все слышитъ его волчье ухо...» $(12,263)$; «Не умретъ волчья кровь слЂпого хана Кучюма» $(12,265)$. Даже враги Кучума - ногаи, искусные наездники, уважительно сравниваются с волчьей стаей:

Пройдетъ въ степи тысяча ногаевъ, а слъдъ какъ отъ десяти всадниковъ, - такъ Ђздятъ ногаи, заклятые враги слЂпого хана Кучюма, точно волчья стая. <...> Зорки глаза у ногаевъ, какъ у ястребовъ, волчье чутье у нихъ... $(12,259)$. 
Враги Кучума из степного племени в повествовании уничижительно сравниваются с собаками:

Но нбть примиренія между костью Тайбуги и костью Ибака, какъ между волкомъ и собакой, и только кровь ихъ льется вмЂстЂ... (12, 262).

Волчьему племени степняков противопоставляется в сказании войско Ермака. О поединке между татарами и русскими говорится:

Вотъ что̀ видъли столътніе глаза Кукджу: каждую ночь на Иртышъ съ татарской стороны выходитъ бълый волкъ, а съ московской черная собака и дерутся до бълаго свђта $(12,247)$.

Особое место в ряду анималистических образов отводится медведю, с которым сравниваются Ермак и его соратники: «...онъ <Кучум> заперъ Ермака въ Искеръ, какъ медвъдя въ каменной берлогъ» $(12,255)$; «Мещерякъ рыщетъ кругомъ, какъ поднятый изъ берлоги медвъдь» $(12,262)$. Во время осады города, занятого войском Ермака, мурза Карача советует Кучуму: «Нужно выманить московскаго медвъдя изъ берлоги» $(12,259)$.

Сравнение русских с медведем, к которому прибегает автор, мотивировано славянской мифологической и фольклорной традицией, в которой, как известно, это животное выступает в качестве тотемного. Вместе с тем медведь представляет собой высший пантеон тотемных животных, почитаемых народами Сибири. Подобное сравнение является признанием мощи войска русского царя, в то же время могучий, но неповоротливый медведь противопоставляется кровожадному и неуловимому степному волку. Обращение к приемам анималистики позволило автору воссоздать колоритные образы героев - носителей мифологических представлений о мире, передать дух изображаемой эпохи.

Важное место в эпосе народов мира занимает комплекс мотивов, связанных с женитьбой героя и продолжением рода. Так, в киргизской сказке «Баймаган» изображается традиционная форма сватовства. Богатый Хайбибула готов отдать свою дочь за калым: 
- Кто дастъ калымъ въ сто лошадей и пятьсотъ рублей деньгами, тому и отдамъ Гольдзейнъ, - хвастается Хайбибула, когда съ гостями напьется кумыса. - Будь хоть безъ головы женихъ, мнъ все равно... Сто лошадей и пятьсотъ рублей деньгами $(12,200)$.

Сам Хайбибула мечтает выгнать старую жену и жениться на молодой:

— <...> Вотъ получу калымъ за Гольдзейнъ и прямо съ деньгами поъду подъ Семипалатинскъ: тамъ въ кошахъ живутъ два брата, Кошгильда и Яшгильда, богатые киргизы, и у обоихъ по молоденькой дочери. Которую хочу, ту и возьму, а тебъ, старой клячъ, пора отдохнуть $(12,200)$.

Таким образом, автор отражает в сказке «Баймаган» сложившиеся у тюркских народов формы брака и сватовства. Обычай многоженства или повторной женитьбы знатного человека преклонных лет на молодой невесте с целью рождения детей связан с кочевым образом жизни, междоусобными войнами, в которых гибли молодые джигиты, потребностью пополнения своего племени молодыми силами.

О подобной форме брака идет речь и в «Сказании о сибирском хане, старом Кучуме». Старая ханша Лелипак-Каныш упрекала своего мужа, хана Кучума:

- <..> Ты браль наложниць - я молчала, ты привелъ вторую жену Симбулу — я молчала; еще четырехъ женъ взялъ я тоже молчала; посльднюю жену, красавицу Сузгэ, привелъ я молчала; всю жизнь провела въ молчаніи $(12,241)$.

Когда иссяк род старого Кучума и Лелипак-Каныш не могла уже подарить ему новых сыновей, старая жена сама уговаривала молодую красавицу Сайхан-Доланьгэ стать женой Кучума, чтобы «продолжилась его волчья кость» $(12,257)$. Именно молодой ханше Сайхан-Доланьгэ отводится роль спасительницы Кучума и его войска, она подарила ему молодых «Кучюмовичей» и новых ратников. Автор прибегает к сказочному приему, соединив силы степи и материнство молодой ханши. Степная трава волшебным образом превращается в воинов, взамен погибших, сама степь встает на защиту сибирского хана Кучума. 
Свершилось великое чудо на глазахъ посла: зашевелилась сорванная ханшей трава, какъ живая... Гдъ-то ударили въ большой бубенъ - и вышли большіе люди; ударили въ малые бубны - вышли простые джигиты. Сколько сорвано было ханшей травы, столько вышло въ поле и джигитовъ. Весело развъваются конскіе хвосты на высокихъ копьяхъ, ржутъ кони, бьютъ бубны, а войско все прибываетъ... Насколько хваталъ глазъ - вездъ изъ земли выходили джигиты $(12,265-266)$.

Сравнение воинских рядов с густой травой является общим для эпоса разных народов. Для примера можно привести фрагмент из Есиповской летописи, в котором описывается сражение войска Ермака с татарами «у реки Иртыша на брегу под Чювашевым»:

И насеяшася множество их, яко травы селнии ${ }^{3}$. И бысть с ними бой велик октября в 23 день, и жняше православное воинство нечестивых божиею помощию, яко же класы ${ }^{4}(90)$.

Уподобление битвы жатве характерно для русской поэтической традиции. Однако нетрудно заметить, что в «Сказании о сибирском хане, старом Кучуме» Мамина-Сибиряка этот вегетативный образ другого культурного происхождения: мифическое войско Кучума уподобляется степной траве, которую не сеют и не жнут, сорванная трава дает жизнь новым воинам, и войско Кучума также безбрежно, как сама степь.

Опираясь на жанровые формы восточных преданий, легенд и сказаний, писатель создает хронотоп, в который вписывает события своих произведений. Главными приметами хронотопа «Сказания о сибирском хане, старом Кучуме» становятся традиционные для тюркского эпоса образы степи и битвы, передающие состояние и картину мира кочевников. Трагические события, связанные с борьбой за Сибирь, изображаются автором не с позиции русских завоевателей, а с точки зрения народа, для которого степь - родное пространство, и этим оправдываются все приносимые жертвы. В финале автор-сказитель воспевает хана Кучума, красавицу ханшу и их сыновей:

Не правда это: живъ старый ханъ Кучюмъ и сейчасъ, онъ бродитъ по степи съ невидимымъ войскомъ. Гдъ онъ прошелъ тамъ лежитъ трава, сорванная ханшею Сайханъ-Доланьгэ. Одинъ 
онъ остался, потому что одинъ не измьнилъ своей матери-степи и искалъ честной смерти въ открытомъ бою съ врагомъ. Вотъ почему, гдъ будетъ въ степи стоять кошъ и гдъ будетъ куриться живой огонекъ, тамъ будетъ пьться и слава старому хану Кучюму, красавиць-ханшъ Сайханъ-Доланьгэ и грознымъ Кучюмовичамъ! $(12,266)$.

Автору «Восточных легенд» удалось встать на позицию тюркоязычного сказителя, отразить образ мыслей, переживаний, отношения к миру инонационального героя. Исследование «Восточных легенд» Д. Н. Мамина-Сибиряка с позиций культурно-исторического, имагологического и мотивного подходов представляется перспективным с точки зрения исследования формы и содержания «тюркского текста» русской литературы.

\section{Примечания}

* Исследование выполнено в рамках проекта РФФИ и правительства Алтайского края «Русская словесность на трансграничном пространстве России и Казахстана: процессы интеграции» (№ 16-14-22002).

1 Полное собрание русских летописей. Том 36: Сибирские летописи. Часть 1: Группа Есиповской летописи. М.: Наука, 1987. С. 82. Далее ссылки на это издание приводятся в тексте статьи с указанием страницы в круглых скобках.

2 Маминъ-Сибирякъ Д. Н. Полное собраніе сочиненій: в 12 т. Пг.: Изд. Т-ва «А. Ф. Марксъ», 1917. Т. 12. С. 204. Далее ссылки на это издание приводятся в тексте статьи с указанием тома и страницы в круглых скобках.

3 Селнии - с греч.: полевые. (Прим. авт.)

4 Класы - с церк.-слав.: колосья. (Прим. авт.)

\section{Список литературы}

1. Артемова Е. Ю. Культура России глазами посетивших ее французов (последняя треть XVIII века). - М.: ИРИ РАН, 2000. — 256 с.

2. Гумилев Л. Древние тюрки [Электронный ресурc]. - URL: https://www. litres.ru/static/trials/00/13/87/00138779.a4.pdf (27.04.2016).

3. Дергачев И. А. Д. Н. Мамин-Сибиряк. Личность и творчество. Свердловск: Средне-Уральское книжное издательство, 1981. - 303 с.

4. Дергачев И. А. Жанр легенды в творчестве Д. Н. Мамина-Сибиряка и пути развития русской литературы в девяностые годы // Русская литература 1870-1890 гг. - Свердловск, 1973. - Сб. 5. - С. 95-118. 
5. Земсков В. Б. Образ России «на переломе времен» (Теоретический аспект: рецепция и репрезентация «другой» культуры) // Новые российские гуманитарные исследования. - 2006. - № 1 [Электронный pecypc]. - URL: http://www.nrgumis.ru/articles/archives/full_art. php?aid=37\&binn_rubrik_pl_articles=238 (27.04.2017).

6. Зырянов О. В. Историческое развитие жанров в контексте литературы регионов // Эволюция жанров в литературе Урала XVII-XX вв. в контексте общероссийских процессов / О. В. Зырянов, Т. А. Снигирева, Е. К. Созина и др. - Екатеринбург: Уральское отделение РАН, 2010. - С. 62-90.

7. Китайник М. Г. Д. Н. Мамин-Сибиряк и народное творчество. - Свердловск: Свердловское книжное изд-во, 1955. - 168 с.

8. Лагунова О. К. Страницы истории Сибири в творчестве Д. Н. МаминаСибиряка // Самотлор. - Тюмень: Типография уприздата, 1975. C. 302-308.

9. Михальская Н. П. Образ России в английской художественной литературе IX-ХІХ вв. - М.: МПГУ, 1995. - 150 с.

10. Михнюкевич В. А. Стилевое течение «поэтизирующего этнографизма» в прозе уральских писателей на рубеже XIX-XX веков // Вестник Челябинского государственного университета. - 1997. - Вып. 1. T. 2. - C. 60-66.

11. Ощепков А. Р. Образ России во французской прозе XIX века: автореф. дис. ... д-ра филол. наук. - М., 2011. - 31 с.

12. Папилова Е. В. Художественная имагология: немцы глазами русских (на материале литературы XIX в.): автореф. дис. ... канд. филол. наук. M., 2013. - 19 c.

13. Приказчикова Е. Е. Мифологическая символика «Восточных легенд» Д. Н. Мамина-Сибиряка и ее связь с проблематикой цикла // Филологический класс. - 2012. - № 4 (30). - С. 26-36.

14. Приказчикова Е. Е. Философский контекст и мифологическая символика «Восточных легенд» Д. Н. Мамина-Сибиряка // Известия Уральского государственного университета. - 2002. - № 24. - С. 65-86.

15. Соболева Л. С. Образы «Слова о полку Игореве» в легенде Д. Н. МаминаСибиряка «Сказание о сибирском хане, старом Кучуме» // Модификации художественных форм в литературном процессе. Д. Н. Мамин-Сибиряк - художник: сб. науч. тр. - Свердловск: УрГУ, 1989. - С. 56-65.

16. Удинцев Б. Д. Фольклор в записных книжках Д. Н. Мамина-Сибиряка. Свердловск: Средне-Уральское книжное издательство, 1966. - 82 с. 
Valentina I. Gabdullina

Altai State Pedagogical University

(Barnaul, Russian Federation)

vigv@mail.ru

\title{
THE TURKIC WORLD OF THE RUSSIAN WRITER: "LEGEND ABOUT THE SIBERIAN KHAN, OLD KUCHUM" BY D. N. MAMIN-SIBIRYAK
}

\begin{abstract}
The article studies the special aspects of the author's conception of the East and the principles of the reconstruction of the way of life and mentality of the Turks in "Eastern legends" by D. N. Mamin-Sibiryak within the context of the general interest the Russian literature of the turn of the 19th and 20th centuries experienced toward orientalism. Based on the "Legend of the Siberian Khan, Old Kuchum" the process of evolution of the poetic stylization into an individual and author's version of the genre form is analyzed, as a result of comprehension, aesthetic mastering and the embodiment of the culture of another nation, folkloristic and mythological figurativeness in the artistic text of the Russian writer. In the "Legend..." there is clearly seen the aspiration of the author to show life of the nomadic people "internally", to look beyond the existing estimative stereotypes about Siberian peoples set in the perception of the Russian in the period of the conquest of Siberia by the troops of the Russian Tsar with ataman Yermak at the head. For the purpose of a comparative analysis the annalistic sources are used (the Esipovsky chronicle). The research is conducted from the perspective of cultural and historical, imagological and motive approaches.
\end{abstract}

Keywords: D. N. Mamin-Sibiryak, “Eastern Legends”, orientalism, genre model, mentality, tradition, imagology

\section{References}

1. Artemova E. Yu. Kul'tura Rossii glazami posetivshikh ee frantsuzov (poslednyaya tret' XVIII veka) [The Culture of Russia Through the Eyes of the French People Who Visited It (The Last Third of the 18th Century)]. Moscow, The Institute of Russian History of the Russian Academy of Sciences Publ., 2000. 256 p. (In Russ.)

2. Gumilev L. Drevnie tyurki [Ancient Turks]. Available at: https://www.litres. ru/static/trials/00/13/87/00138779.a4.pdf (accessed 27 April 2017). (In Russ.)

3. Dergachev I. A. D. N. Mamin-Sibiryak. Lichnost' i tvorchestvo [D. N. Mamin-Sibiryak. Personality and Creative Work]. Sverdlovsk, Middle Urals Book Publishing House, 1981. 303 p. (In Russ.)

4. Dergachev I. A. The Genre of Legend in the Works of D. N. Mamin-Sibiryak and the Ways of Development of Russian Literature in the 1890s. In: Russkaya literatura 1870-1890 godov, Sverdlovsk, 1973, collection 5, pp. 95-118. (In Russ.)

5. Zemskov V. B. The Image of Russia "at the Turn of Epochs" (Theoretical Aspect: Reception and Representation of the "Other" Culture. In: Novye 
rossiyskie gumanitarnye issledovaniya, 2006, no. 1. Available at: http://www. nrgumis.ru/articles/archives/full_art.php?aid=37\&binn_rubrik_pl_articles $=238$ (accessed 27 April 2016). (In Russ.)

6. Zyryanov O. V. Historical Development of Genres in the Context of Regional Literature. In: Evolyutsiya zhanrov v literature Urala XVII-XX vekov [Evolution of Genres in the Urals Literature of the 17th-20th Centuries]. Yekaterinburg, Urals Branch of the Russian Academy of Sciences Publ., 2010, pp. 62-90. (In Russ.)

7. Kitaynik M. G. D. N. Mamin-Sibiryak i narodnoe tvorchestvo [D. N. Mamin-Sibiryak and Popular Art]. Sverdlovsk, Sverdlovsk Book Publishing House, 1955. 168 p. (In Russ.)

8. Lagunova O. K. Stranitsy istorii Sibiri v tvorchestve D. N. Mamina-Sibiryaka [The Pages of Siberian History in the Works of D. N. Mamin-Sibiryak]. Tyumen, Tipografiya uprizdata Publ., 1975, pp. 302-308. (In Russ.)

9. Mikhal'skaya N. P. Obraz Rossii v angliyskoy khudozhestvennoy literature IXXIX vekov [The Image of Russia in the English Fiction Literature of the 9th-19th Centuries]. Moscow, Moscow State Pedagogical University Publ., 1995. 150 p. (In Russ.)

10. Mikhnyukevich V. A. The Style of "Poetizing Ethnography" in the Prose of the Urals Writers at the Turn of the 19th-20th Centuries. In: Vestnik Chelyabinskogo gosudarstvennogo universiteta [Bulletin of Chelyabinsk State University], 1997, issue 1, vol. 2, pp. 60-66. (In Russ.)

11. Oshchepkov A. R. Obraz Rossii vo frantsuzskoy proze XIX veka. Avtoref. dis... doctora filol. nauk [The Image of Russia in the French Prose of the 19th Century. PhD. philol. sci. diss. abstract]. Moscow, 2011. 31 p. (In Russ.)

12. Papilova E. V. Khudozhestvennaya imagologiya: nemtsy glazami russkikh (na materiale literatury XIX v.). Avtoref. dis. ... kand. filol. nauk [Artistic Imagology: Germans Through the Eyes of Russians (Based on Literature of the 19th Century). PhD. philol. sci. diss. abstract]. Moscow, 2013. 19 p. (In Russ.)

13. Prikazchikova E. E. Mythological Symbolics of D. N. Mamin-Sibiryak's "Oriental Legends" and Its Relation to the Problems of the Cycle. In: Filologicheskiy klass, 2012, no. 4 (30), pp. 26-36. (In Russ.)

14. Prikazchikova E. E. Philosophical Context and Mythological Symbolism of "Oriental Legends" by D. N. Mamin-Sibiryak. In: Izvestiya Uralskogo gosudarstvennogo universiteta [Proceedings of the Ural State University], 2002, no. 24, pp. 65-86. (In Russ.)

15. Soboleva L. S. Images of "The Tale of Igor's Campaign" in the "Legend of the Siberian Khan, Old Kuchum" by D. N. Mamin-Sibiryak. In: Modifikatsii khudozhestvennykh form v literaturnom protsesse. D. N. Mamin-Sibiryakkhudozhnik: Sbornik nauchnykh trudov [Modifications of Artistic Forms in the Literary Process. D. N. Mamin-Sibiryak - Artist: Collection of Scientific Works]. Sverdlovsk, Ural State University Publ., 1989, pp. 56-65. (In Russ.)

16. Udintsev B. D. Fol'klor v zapisnykh knizhkakh D. N. Mamina-Sibiryaka [Folklore in the Notebooks of D. N. Mamin-Sibiryak]. Sverdlovsk, Middle Urals Book Publishing House, 1966. 82 p. (In Russ.) 